\author{
MICHAEL C. LOVELL
}

Wesleyan University

\title{
Why Was the Consumer Feeling So Sad?
}

THE INDEX of consumer sentiment, compiled quarterly by the University of Michigan's Survey Research Center since 1953, dropped to an unprecedented low of 71.8 in the third quarter of 1973; by the beginning of 1975 it had slumped to $58 .{ }^{1}$ Why was the consumer feeling so sad? Certainly, there was no lack of provocation. Watergate, widespread unemployment, double-digit inflation, and the collapse of the stock market provided cause enough for consumer despondency. Investigations by Hymans and by Juster and Wachtel had suggested that inflation and fluctuations in real income are of prime importance in explaining consumer sentiment; but they did not include the unemployment rate in their regressions. This note updates their studies in the light of recent experience. ${ }^{2}$ Because the mood of the consumer, as measured by Katona's index of consumer sentiment, has been identified by Suits and Sparks, by Hymans, and by Juster and Wachtel as an important determinant of consumer spending, ${ }^{3}$ a study of

Note: I am indebted to Eric Postel for efficiently executing the computations reported in this paper on the Wesleyan DEC-10 computer.

1. First quarter $1966=100$.

2. Saul H. Hymans, "Consumer Durable Spending: Explanation and Prediction," $B P E A, 2: 1970$, pp. 173-99; F. Thomas Juster and Paul Wachtel, "Inflation and the Consumer," $B P E A, 1: 1972$, pp. 71-114. The literature on the consumer-sentiment variable is critically summarized in R. William Thomas, "The Effect of Averaging Components on the Predictability of the Index of Consumer Sentiment," Review of Economics and Statistics, vol. 57 (February 1975), pp. 684-91. Back data on the index are tabulated in Business Conditions Digest (January 1975), p. 110.

3. Daniel B. Suits and Gordon R. Sparks, "Consumption Regressions with Quarterly 
the factors in the disillusionment of consumers may help to explain the severity of the current recession.

The simplest explanation for consumer disillusionment is the economic discomfort index, obtained by summing the unemployment rate and the annual rate of inflation. This index, discussed in the past in the Wall Street Journal, which attributed it to Arthur Okun, and published by Data Resources, Inc., is plotted in figure 1 along with the index of consumer sentiment. ${ }^{4}$ Regressing the index of consumer sentiment $(I C S)$ on the economic discomfort index $(E D I)$ yields ${ }^{5}$

$$
I C S=\underset{(1.8)}{113.5}-\underset{(0.201)}{2.987 E D I}+e,
$$

$$
\begin{gathered}
\bar{R}^{2}=0.746 ; \text { standard error }=5.299 ; \text { Durbin-Watson statistic }=0.547 ; \\
\text { number of observations }=76 .
\end{gathered}
$$

where

$$
\begin{aligned}
E D I= & U+\dot{P} \\
U= & \text { the unemployment rate } \\
\dot{P}= & 100\left(C P I / C P I_{-4}-1\right)=\text { the annual percentage change in the } \\
& \text { consumer price index } \\
e= & \text { error term. }
\end{aligned}
$$

Data," in James S. Duesenberry and others, eds., The Brookings Quarterly Econometric Model of the United States (Rand McNally, 1965); Hymans, "Consumer Durable Spending"; Juster and Wachtel, "Inflation and the Consumer."

4. This index is not without precedent. Rostow constructed a "social tension" index for England covering the years 1790-1850 by summing an index of the severity of the business cycle and an index of the level of wheat prices, both coded on a 1-to-5 scale. He noted that intervals of "high social tension" identified by the index coincided with known symptoms of unrest. See W. W. Rostow, British Economy of the Nineteenth Century (London: Oxford University Press, 1948), pp. 123-25. The DRI economic discomfort index is analogous to Earl C. Thom's temperature-humidity index (THI), introduced by the U.S. Weather Bureau in 1959:

$$
T H I=15+0.4\left(t+t^{w}\right) .
$$

Here $t$ is fahrenheit temperature and $t^{w}$ is wet-bulb temperature; the lower the humidity, the more rapid the evaporation, the lower $t^{w}$, and the more comfortable the level of the $T H I$. With $T H I=70,10$ percent of the population feels uncomfortable; at $T H I=75$, 50 percent complain.

Another measure is the sum of the current year's inflation rate and the preceding year's unemployment rate, plotted by the Committee for Economic Development in High Employment without Inflation: A Positive Program for Economic Stabilization (CED, July 1972), p. 12.

5. There are only seventy-six observations for the regression period of 1954:1 through 1975:1 because the ICS data are available only sporadically in the earlier years. 


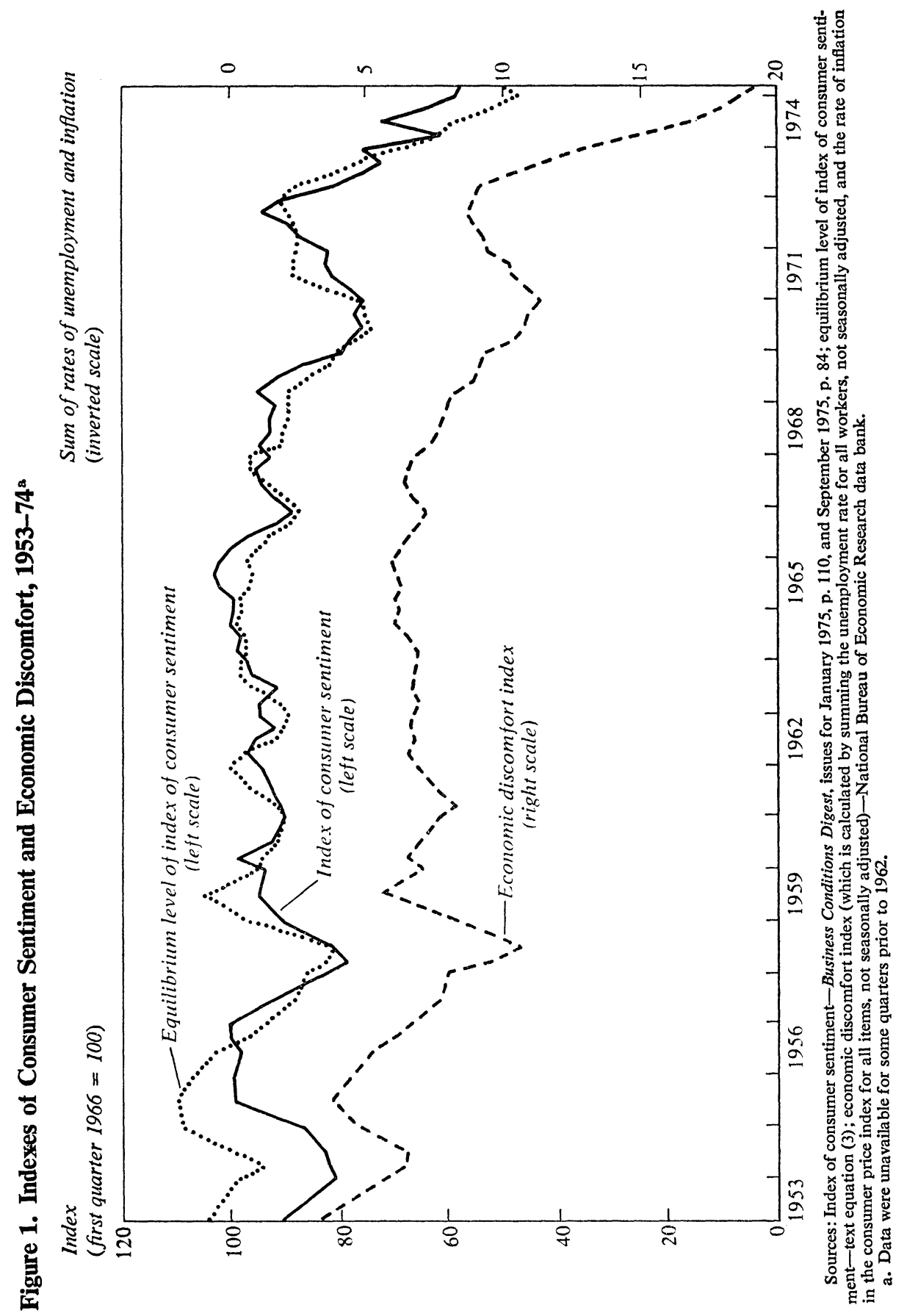


Here and in subsequent equations, the numbers in parentheses are standard errors. Evidently, the assumption that unemployment and inflation contribute equally provides a useful first approximation in explaining movements in the index of consumer sentiment. ${ }^{6}$

The discomfort-index regression is recommended primarily by its simplicity. The following regression distinguishes the effects of the unemployment rate $(U)$ and inflation $(\dot{P})$ :

$$
\begin{aligned}
& I C S= 41.28-1.23 \dot{P}-0.883 U+0.0886 S P+0.627 I C S_{-1}+e . \\
&(10.17) \quad(0.31) \quad(0.499) \quad(0.0429) \quad(0.086) \\
& \bar{R}^{2}= 0.902 ; \text { standard error }=3.34 ; \text { Durbin-Watson statistic }=2.27 ; \\
& \text { number of observations }=64 .
\end{aligned}
$$

The effect of movements in the stock market is captured by $S P$, the annual percentage change in the Standard and Poor index of stock prices. Last quarter's value of the index of consumer sentiment $\left(I C S_{-1}\right)$ is included to capture two types of lags: First, the impact of adverse economic conditions upon a consumer's morale is likely to be stronger the longer those conditions have persisted. Second, disillusionment is contagious, and a larger proportion of consumers may "catch" it as time passes, possibly by reading about last quarter's index of consumer sentiment in the newspaper. Observe that the index of consumer sentiment is much more sensitive to inflation than to fluctuations in the stock market. Thus, in 1974:4, when $S P=$ -33.0 percent and $\dot{P}=12.2$ percent, the regression suggests that doubledigit inflation reduced $I C S$ by 15.0 points while the stock-market collapse cost 2.9 points. Taken at face value, the regression suggests that a rise of 1 percentage point in the unemployment rate cuts 0.883 point off the ICS. However, the coefficient on the unemployment rate is less than twice its standard error, and, it turns out, does not differ significantly from the coefficient for $\dot{P}$; that is to say, looking at the ability of the discomfort index to explain the index of consumer sentiment, one finds no reason to reject the simple assumption that the contribution of unemployment and inflation to consumer disillusionment is proportional to their sum. ${ }^{7}$

The coefficients of this last regression reveal the short-run determinants of consumer sentiment, given $I C S_{-1}$. In the long run, when the index of consumer sentiment has stabilized so that $I C S=I C S_{-1}$ at an equilibrium value, $I C S^{e}$, then

6. When the rate of inflation is computed by taking the quarterly change at annual rates rather than the annual change, the regression yields $\bar{R}^{2}=0.584$.

7. The standard error of the 0.347 difference $(1.23-0.883)$ is 0.470 . 


$$
I C S^{e}=110.67-3.30 \dot{P}-2.37 U+0.238 S P .
$$

This suggests

$$
I C S_{t}=0.373 I C S^{e}+0.627 I C S_{-1}+e,
$$

or

$$
I C S_{t}-I C S_{t-1}=0.373\left(I C S^{e}-I C S_{-1}\right) .
$$

Thus, contagion and inertia are gradually overcome as the index of consumer sentiment converges toward its equilibrium level, eliminating about 37 percent of the gap between equilibrium and actual ICS each quarter. The $I C S^{e}$ series, also plotted in figure 1, may measure consumer discomfort more precisely than the $E D I$.

The unemployment rate reflects directly the condition of only the unemployed fraction of the labor force; but indirectly it may capture the effect of a shortened workweek and the uncertainty generated by the threat of layoffs. An alternative to the unemployment measure is the GNPGAP, the percentage by which actual GNP falls short of the economy's potential output.

$$
\begin{gathered}
I C S=34.8+1.138 \dot{P}-0.197 \text { GNPGAP }+0.080 S P \\
(8.8) \quad(0.306)(0.155) \\
+0.656 I C S_{-1}+e . \\
(0.086) \\
\bar{R}^{2}=0.899 ; \text { standard error }=3.38 ; \text { Durbin-Watson statistic }=2.312 ; \\
\text { number of observations }=64 .
\end{gathered}
$$

The GNPGAP, like the unemployment variable it replaces, has the appropriate negative sign; it is also less than twice its standard error. The equation is not quite as tight as it is when the unemployment variable is used, but the difference is not marked.

Several variations on regression equation (2) were considered in an attempt to find out more about the determinants of consumer sentiment. First, the annual rate of change in the weekly real wage was added in order to determine whether the depressing effect of inflation may be offset by compensating changes in the money wage, as might be achieved by indexing; however, the real-wage $t$-coefficient of -0.056 suggested that during inflationary episodes the consumer becomes depressed regardless of whether real wages are maintained. ${ }^{8}$ Second, the rate of anticipated inflation,

8. Of course, even if the money wage is adjusted so as to keep pace with inflation, consumers who are net creditors may nonetheless suffer from unanticipated capital losses. In his earlier study Hymans used a measure of the rate of change in aggregate disposable 
rather than recent inflationary experience, might be critical; when a Survey Research Center estimate of anticipated inflation was added to the regression it had an unexpected positive coefficient, but it was small relative to its standard error. ${ }^{9}$ Third, quadratic terms were added to equation (2) in an attempt to capture nonlinearities, but without success. ${ }^{10}$ Fourth, in an attempt to determine whether a general post-Vietnam and post-Watergate malaise might explain the despondency of the consumer better than economic factors, a dummy variable was added that equaled zero except for the post-1973:3 observations; it had an unexpected positive sign and was very small relative to its standard error.

Finally, following a suggestion of Lawrence Klein, the change in the unemployment rate was added, yielding ${ }^{11}$

$$
\begin{gathered}
I C S=46.08-1.35 \dot{P}-0.55 U-2.97\left(U_{t}-U_{t-1}\right) \\
(10.07)(0.31)(0.50)(1.32) \\
+0.053 S P+0.561 C S_{-1}+e . \\
(0.0445) \quad(0.088) \\
\bar{R}^{2}=0.908 ; \text { standard error }=3.20 ; \text { Durbin-Watson statistic }=2.09 ; \\
\text { number of observations }=64 .
\end{gathered}
$$

real income net of transfer payments, but not the unemployment rate, in studying the determinants of the $I C S$; the strongest result for this variable involved a $t$-coefficient of 1.72 and an $\bar{R}^{2}$ of 0.796 . Refitting regression (2) over Hymans' sample period led to $\bar{R}^{2}=0.822$; the regression coefficients were essentially the same as over the longer sample period. See Hymans, "Consumer Durable Spending," p. 177.

9. Adding anticipated inflation did make the $t$-coefficient of $U$ larger and increased the magnitude of the coefficient of realized inflation. Juster and Wachtel used the anticipated rate of inflation in their study of the determinants of the ICS; they also obtained a perverse positive sign. Their largest $\bar{R}^{2}$ was 0.903 ; when equation (2) is refitted over their sample period, an $\bar{R}^{2}$ of 0.907 is obtained. They excluded unemployment as well as Hymans' real output measure from their regressions. See Juster and Wachtel, "Inflation and the Consumer," p. 97.

10. At face value the linear form of equation (2) implies that the 1929-33 collapse was not so bad after all, in that record unemployment was partially offset by deflation; however, the sample period for the present study does not include sufficient observations on price declines. Lepper's study of voter behavior indicated that the direction of price change was critical over her 1896-1964 sample period. See Susan J. Lepper, "Voting Behavior and Aggregate Policy Targets," Public Choice, vol. 18 (Summer 1974), pp. 67-81.

11. F. Gerard Adams and Lawrence R. Klein report a $t$-coefficient of -4.09 on the change in unemployment for the 1953:3-1970:1 estimation period in "Anticipations Variables in Macro-Econometric Models," in Burkhard Strumpel, James N. Morgan, and Ernest Zahn, eds., Human Behavior in Economic Affairs: Essays in Honor of George Katona (Jossey-Bass, 1972), p. 299. 
Evidently, abrupt increases in unemployment are particularly distressing, but the public may eventually become numb to continued stagnation.

To sum up, consumer despondency is not to be explained by the general social malaise in the aftermath of Vietnam and Watergate. The primary explanation lies in the inflation; unemployment and the collapse of the stock market play lesser roles. Fluctuations in the rate of growth of the real wage are not critical. And if consumer sentiment does have a strong influence on durable spending, the analysis suggests that the cost-push forces contributing to double-digit inflation may have made a decisive contribution to the severity of the current recession.

One possible moral of this story is that it may be good politics for the President to worry more about inflation than unemployment. This might be a mistake, for Mueller's study of survey data on presidential popularity and follow-up work by Kalos indicate that unemployment is the more salient variable. ${ }^{12}$ The acid test is at the polls, and Kramer reports that unemployment consistently enters with the wrong sign in explaining the outcome of congressional elections. Real income did most of the work, but George Stigler argued that this result arose from errors in the income series. ${ }^{13}$ Stigler, with an argument from Okun, asserted that the policies of the parties with regard to income distribution should be the critical factor because Democrats and Republicans are identically committed to the pursuit of full employment and growth in real income. ${ }^{14}$

12. Mueller's only economic variable was a slump measure. Kalos reports that between 2.5 and 3 points of presidential popularity are sacrificed for each percentage point of increase in unemployment; a 1 percent drop in the rate of change in real income would cost between 0.8 and 1.5 points; an increase of 1 percentage point in the rate of inflation would cost between 0.3 and 0.8 point. See John E. Mueller, War, Presidents and Public Opinion (Wiley, 1973); and Stephen H. Kalos, "The Economics of Presidential Popularity: An Empirical Test" (B.A. thesis, Wesleyan University, 1973).

13. Gerald H. Kramer, "Short-Term Fluctuations in U.S. Voting Behavior, 18961964," American Political Science Review, vol. 65 (March 1971), pp. 131-43; George J. Stigler, "General Economic Conditions and National Elections," American Economic Review, vol. 63 (May 1973), pp. 160-67.

Ray C. Fair reports that the growth rate of current real GNP per capita is the best variable for explaining the outcome of presidential elections; see "On Controlling the Economy to Win Elections," Discussion Paper 397 (Cowles Foundation, 1975; processed).

14. See Stigler, "General Economic Conditions," and Arthur M. Okun, "Comments on Stigler's Paper," American Economic Review, vol. 63 (May 1973), pp. 172-77. 